\title{
Factors Affecting Self-discipline as Good Citizens for the Undergraduates of Chiang Mai University in Thailand: A Multilevel Path Analysis
}

\author{
Suntonrapot Damrongpanit \\ Department of Fundamental and Development in Education, Chiang Mai University, Thailand
}

Copyright(C2019 by authors, all rights reserved. Authors agree that this article remains permanently open access under the terms of the Creative Commons Attribution License 4.0 International License

\begin{abstract}
The objective is to examine the factors, which affect self-discipline as good citizens for undergraduates. The samples were employed with 1,407 undergraduates from 18 faculties by Stratified Random Sampling. The instrument was 5-rating-scale questionnaire consisting of 89 items for self-discipline as good citizens and 84 items for measuring 9 causal factors classified as 5 aspects of student level and 4 aspects of faculty level. A Multilevel Path Analysis was used for data analysis by Mplus 7.4 program. The results showed that the democratic child rearing, the discipline prototype, and the discipline environment had positive effects. On the other hand, the media effect and the discipline climate had the negative effects on self-discipline. All factors explained variances of self-discipline between student and faculty were $39.90 \%$ and $98.40 \%$, respectively.
\end{abstract}

Keywords Self-discipline, Citizenship, Child Rearing, Self-control, Multilevel Path Analysis

\section{Introduction}

Self-discipline is one qualification for all societies and all people needed. Countries with self-disciplined citizens also reflect directly to quality of societies as the crucial drive in developing and competing internationally [27].

When we consider basic principles, a group of the students at the higher education level, having matriculated through a system of knowledge, skills, and ideal characteristics for at least 12 years should reflect basic societal values. Therefore, all stakeholders expect the disciplined undergraduates before entering society as good citizens ([28]; [7]). As the fact that there are many factors making them different from expectation, it is equally challenging when searching for answers to youth discipline problems in the societies presently.
Chiang Mai University is a regional university in Thailand, ranked as a leading research and academic university. Each year, students are enrolled in 21 faculties with a high student selection mechanism continuously. After the students have been selected, there was the chronic problem of students related to inappropriate behavior by the discipline department (the department responsible for student discipline). Various types of breaches of disciplinary prohibitions have been reported such as exam cheating, document and signature forgery as well as the destruction of property and violation of the use of prohibited places. According to the record, the disciplinary problems have not decreased although activities promoting discipline have been organized frequently both in faculty and university levels. Therefore, this situation reflects to the responsible people that the high selection of the students does mean anything about moral and self-discipline. This also has the question whether the activities developing students in the university period can develop them to be good quality citizens or not. These stimulate all parties to review the significant causes both of students' background and factors relating to have a seat in the university seriously.

Based on the review of the background, the child rearing style is an important element in the development of children from pre-school since the family is a complex structure with the interaction between members, and learning from each other before shaping their own personal style [30]. Child rearing styles are varied on 3 styles [22], one of these styles is parents use rules with family members along with explaining the reasons, checking out the understanding of the peace in the family. This style is called "Authoritative" which helps to improve moral and competency in the high level society among children. Some researcher indicates this style as "democratic child rearing" ([29]; [2]; [20]). The results of the important study suggest that parenting in such a way also allows the children to have an attitude of respect for social norms, 
self-control behavior, self-confidence, great social skills, being ethical and respectful of others over personal interests, including the proficiency in studying of the high level ([33]; [30]; [18]; [35]). These all characteristics have also become important factors in promoting self-discipline as well.

Not only the background factor, but also environmental factors that affect self-discipline during the university entrance [32]. The essential key to explaining learning from the environment comes from Bandura's concept [4] that is called "Social Cognitive Theory". This theory explains that human learning bears from observation, imitating, and understanding things around them, such as behavioral patterns, verbal communication, symbols, and touching the model. When linking to the campus life of students, it can be concluded that four main factors are influencing self-discipline: 1 ) the self-discipline prototype ([31]; [23]) from close friends and instructors, who are close to and have the role in daily interaction; 2) the discipline environment ([30]; [8]; [16]) 3) the discipline climate ([34]; [15]; [10]), both in the form of teaching activities and curricula, and 4) the media effect ([25]; [19]; [31]; [16]), especially public media disseminating knowledge and entertainment through various channels such as television, radio, and portable electronic media via online media. Each factor gains the interest and is used in a study that describes the students' behavior; therefore, it is the researcher's expectation that the relationship between these factors may help to explain self-discipline and to help students to develop an actual problem-solving approach.

\section{Methodology}

\subsection{Research Goal}

The researcher is interested in examining the factors influencing self-discipline of undergraduates by synthesizing the theoretical concepts and research. The researcher classifies the causal relationship and links the relationship between the factors influencing student self-discipline) DIS (divided into the structure of various factors as the multilevel model and classified into 2 levels : 1) Student level consists of 5 main factors: 1.1) Leadership (LED), 1.2) Discipline Motivation (MOT) (affects both DIS and LED), 1.3) Self-confidence (CON) (affects DIS, LED, and PRO), 1.4) Attitude toward Discipline (ATT) (affects DIS, LED, CON, and PRO), and 1.5) Democratic Child Rearing (DEM) (affects all variables at student level): 2) Faculty level consists of 4 main factors: 2.1) Discipline Prototype (PRO), 2.2) Discipline Climate (CLI) (affects DIS, PRO and ATT), 2.3) Discipline Environment (ENV) (affects DIS, PRO CLI, and ATT), and 2.4) Media Effect (MED) (affects all faculty variables). Additionally, the researcher expects that this hypothetical model will be congruent with the empirical data collected from undergraduate students of Chiang Mai University.

\subsection{Sample and Data Collection}

The samples were 1,407 undergraduates who have currently studies in $1^{\text {st }}$ year to $6^{\text {th }}$ year from 18 faculties who were selected according to the stratified random sampling and the faculties were as strata in random from the population of 25,152 undergraduates, classified as 585 male students (41.578\%) and 822 female students $(58.422 \%)$. Most of them was from Faculty of Education (13.362\%), followed by Faculty of Engineering (12.082\%), and Faculty of Humanities and Social Sciences (9.524\%), respectively. The sample size was done by estimating the sample size 10 times to one parameter value of the hypothesized model [14]. The parameter value in the model was totally 64 values. The sample size should be at least 640. The results of the data collection were more than one estimate of the estimated data. Therefore, the proportion of students from a population and the random sampling in each faculty had the positive relationship with the high level (Pearson's correlation coefficient $=0.743$ ).

Each student had a 5-point rating scale questionnaire ( $1=$ Strongly Disagree and $5=$ Strongly Agree). It was divided into 2 parts. The first one consisted of 89 self-discipline items covering 4 main aspects of the model as responsibility, honesty, and the practice of rules, tolerance, and intention, by definition. However, the scope of the definition, and measurement of the 4 variables were linked to the internal and external performance of the university as students and good citizens. The results of the instrument test with the students for the quality of the questionnaire found that the item discrimination index of the item-total correlation $\left(\mathrm{r}_{\mathrm{xy}}\right)$ was between 0.219-0.896. The reliability of each aspect based on the Cronbarch's Alpha Coefficient $(\alpha)$ was between 0.826-0.946.

Part two was a collection of information about factors affecting DIS as 9 factors classified into two levels: "the student level" and "the faculty levels". There were 5 factors of student level 1: MOT (13 items) means the commitment to success and have tolerance with the difficulties, have ambition for success, know the actual ability, and always set goals in life $\left.\left(r_{x y}=0.315-0.637, \alpha=0.834\right), 2\right) \operatorname{CON}(7$ items) means physical courage, confidence in thinking and acting on their own and others $\left(\mathrm{r}_{\mathrm{xy}}=0.293-0.513, \alpha=0.685\right)$, 3) LED (15 items) means selflessness, sportsmanship, reasoning, forgiveness, and acceptance from others as well $\left.\left(r_{x y}=0.328-0.602, \alpha=0.835\right), 4\right)$ ATT (8 items) means recognizing the value of discipline in society, appreciate individuals and societies with disciplined members. They also need to maintain discipline for their self-restraint and society $\left(r_{x y}=0.206-0.627, \alpha=0.660\right)$, and 5) DEM (16 items) refers to the manner in which the expression and the methods used in the teaching of the student are equitable, accepted the thoughts and talents of students, use rules with reasons, love and warmth $\left(\mathrm{r}_{\mathrm{xy}}=0.482-0.719, \alpha=0.922\right)$. 
According to the faculty and university levels were 4 factors: 1) PRO (7 items) means physical behavior and thinking about discipline in both teaching and daily lives from peers and instructors $\left.\left(\mathrm{r}_{\mathrm{xy}}=0.437-0.669, \alpha=0.761\right), 2\right)$ MED ( 8 items) is the content, the story and the symbols that have been conveyed through social media channels. It represents a role model for raising awareness, social values, attitudes, and self-discipline $\left(\mathrm{r}_{\mathrm{xy}}=0.415-0.650\right.$, $\alpha=0.781$ ), 3) CLI (6 items) is the development of discipline in various forms of faculties and university besides the content-oriented instructional management $\left(\mathrm{r}_{\mathrm{xy}}=0.450-0.749, \alpha=0.867\right)$, and 4$) \mathrm{ENV}$ (5 items) refers to the physical characteristics representing a concise communication in practicing the discipline to educate and clarify the correct practice including the orderly landscape that helps to be peaceful to the students $\left(\mathrm{r}_{\mathrm{xy}}=0.359-0.540\right.$, $\alpha=0.753$ ).

\subsection{Data Analysis}

The statistical approach used for the data analysis was Multilevel Path Analysis (MPA) because the data structure of the variables was hierarchical data in term of students within faculties and faculties within the same university. The main principle was to divide the variance of the variables into subgroups in accordance with the degree of hierarchy of the analysis unit such as student level or within a level (analysis unit is students) and faculty level or between level (analysis unit is a faculty or mean scores measured by variable of students in the same faculty). In this case, it can identify the analysis into 2 levels, as well as the mediating pathway between the independent variables and the dependent variables, which showed the estimated effect into 3 parts as Direct Effect (DE), Indirect Effect (IE), and Total Effect (TE) [TE=DE+IE, and IE gained from the possibly total results specific IE from particular factor and DIS]. The results showed that the hypothetical model is appropriately assessed using MPA by considering the ICC value (Intra-Class Correlation), which is defined as the degree of similarity between the students in the same faculty or the proportion between the group variance divided by the total variance, ranging from 0 and 1 (ICC $>0.05$ is preferable to use the MPA with that particular data instead). In addition, goodness of fit of the hypothetical model and the empirical data was estimated from the comparative fit index $(\mathrm{CFI})>0.95$, root mean square error of approximation (RMSEA) $<0.06$, standardized root means square error of approximation $($ SRMR) $<0.08$ ([13]; [14]). The MPA analysis used the MLR estimation method, which was valid even if the data had a non-regular distribution pattern with a program of Mplus 7.4 [24].

\section{Results}

The preliminary information from Table 1 shows an average of DIS at 1.818, which is relatively low. The mean of all other factors was significantly higher than DIS, especially between level factors had the mean over than 3.00 in all factors. The relationship between variables of all the factors in the model as a whole from the total 45 pairs under sub-diagonal revealed that 32 pairs of the Pearson's correlation coefficient $\left(r_{\mathrm{xy}}\right)$ were significantly different from zero. DIS has positive, statistically significant relationship with all other factors at .01 in within level. However, there was a tendency of the negative relationship with factors between level that were statistically significant at the very negative low level of .05 with a single factor; media factor. Moreover, the relationship between independent variables at the same level of all pairs was statistical significance at .01 level. They had a positive relationship with statistical significance of moderate level to the highest level factors at $.01 \quad\left(\mathrm{r}_{\mathrm{xy}}\right.$ within level= $0.330-0.656$ and between level $=0.408-0.860)$; whereas, there were 11 pairs had the cross-level correlation coefficient that were statistically significantly different from zero. Most of them had the low positive direction. The attitude factor toward discipline and disciplinary leadership variables were statistically significant in relation to all factors at the faculty level. 
Table 1. Correlation Matrix, Mean, and Standard Deviation of variables

\begin{tabular}{|c|c|c|c|c|c|c|c|c|c|c|}
\hline & 1 & 2 & 3 & 4 & 5 & 6 & 7 & 8 & 9 & 10 \\
\hline 1 DIS & 1.000 & & & & & & & & & \\
\hline $2 \mathrm{MOT}$ & $0.530 * *$ & 1.000 & & & & & & & & \\
\hline $3 \mathrm{ATT}$ & $0.324 * *$ & $0.379 * *$ & 1.000 & & & & & & & \\
\hline 4 DEM & $0.501 * *$ & $0.440 * *$ & $0.333^{* *}$ & 1.000 & & & & & & \\
\hline $5 \mathrm{CON}$ & $0.460 * *$ & $0.593 * *$ & $0.330 * *$ & $0.409 * *$ & 1.000 & & & & & \\
\hline 6 LEA & $0.546 * *$ & $0.656^{* *}$ & $0.553 * *$ & $0.488^{* *}$ & $0.605^{* *}$ & 1.000 & & & & \\
\hline 7 PRO & 0.044 & 0.038 & $0.085^{* *}$ & 0.032 & 0.025 & $0.095 * *$ & 1.000 & & & \\
\hline $8 \mathrm{ENV}$ & -0.029 & $0.060^{*}$ & $0.081 * *$ & 0.043 & -0.013 & $0.083^{* *}$ & $0.408 * *$ & 1.000 & & \\
\hline 9 MED & $-0.059^{*}$ & $0.073^{* *}$ & $0.107 * *$ & 0.023 & 0.033 & $0.102 * *$ & $0.454 * *$ & $0.720 * *$ & 1.000 & \\
\hline $10 \mathrm{CLI}$ & -0.039 & 0.046 & $0.083^{* *}$ & 0.032 & -0.021 & $0.067^{*}$ & $0.494 * *$ & $0.860 * *$ & $0.663 * *$ & 1.000 \\
\hline Mean & 1.818 & 2.686 & 2.832 & 3.009 & 3.616 & 2.455 & 3.687 & 3.502 & 3.495 & 3.436 \\
\hline SD & 0.199 & 0.290 & 0.407 & 0.451 & 0.483 & 0.286 & 0.081 & 0.117 & 0.108 & 0.105 \\
\hline
\end{tabular}

Note: $* \mathrm{p}<.05, * * \mathrm{p}<.01$

The results of MPA revealed that the ICC value is 0.065 (the average sample size for each group is 70.350). This can be used to calculate a strong design effect as 5.508, which indicated that the variance of DIS has a significant difference between the faculties and the appropriateness of using the MPA as planned. Moreover, the hypothetical model was consistent with the empirical data at a good level which showed the important index as $\chi^{2}=60.511$, df $=25, \quad \chi^{2} / \mathrm{df}=2.420, \quad \mathrm{p}=0.000, \quad \mathrm{CFI}=0.998, \quad \mathrm{TLI}=0.986$, RMSEA $=0.032, \quad$ SRMR-Within $=0.029, \quad$ and SRMR-Between $=0.284$.

As student-level found that the DEM has the standardized total effect on DIS of the students in the most positive direction ( $(\beta=0.484)$, followed by MOT $(\beta=0.294)$, CON $(\beta=0.273)$, LED $(\beta=0.212)$ and ATT $(\beta=0.191)$, respectively. Furthermore, the DEM also had DE and IE in the highest standardized total effect of the student level. The main IE had 3 ways as 1) the path from $\mathrm{DEM} \rightarrow \mathrm{MOT} \rightarrow \mathrm{DIS} \quad(\beta=0.044), \quad 2) \quad$ the path from $\mathrm{DEM} \rightarrow \mathrm{CON} \rightarrow \mathrm{MOT} \rightarrow \mathrm{DIS} \quad(\beta=0.034)$, and 3$)$ the path from $\mathrm{DEM} \rightarrow \mathrm{LED} \rightarrow \mathrm{DIS}(\beta=0.031)$. While there were the other effects from other paths, most of the coefficients of the paths in the positive direction were statistically significant at very low levels. All of 5 factors in the student level could explain the variance of determination $\left(\mathrm{R}^{2}\right)$ of each student at 39.90 percent.

According to the results of the faculty level, the total effect of 4 factors could be classified into three categories: 1) positive TE was found that only one factor of the discipline model showed the DE (and TE) in positive path $(\beta=0.195), 2)$ negative TE is the media effect $(\beta-=0.956)$, which showed the path coefficients in the negative direction both $\mathrm{DE}$ and IE (the most negative was the path from $\mathrm{MED} \rightarrow \mathrm{ENV} \rightarrow \mathrm{CLI} \rightarrow \mathrm{DIS})$ and the $\mathrm{CLI}$, which represented the path coefficients in the negative direction for $\mathrm{DE}$ and in a positive direction for IE, and 3) no significance of TE from ENV; however, there were positively significant of DE and negatively in IE. All 4 factors of the faculty level shared the variance of each student in each faculty by 98.40 percent.

The researcher found the cross-level interaction between the faculty and student independent variables .Initially, the ICC of discipline attitude was 0.014 , which indicated that there is a difference in ATT among students. The students' ATT was positively influenced by ENV in each group $(B=0.545)$, but there was the negative effect of CLI in each faculty $(\beta-=0.939)$. However, both variables at the faculty level could describe the students' ATT variance as 32.70 percent. The estimated details of all values are shown in Table 2. and Figure. 1. 
Table 2 . Estimated Results of Parameter for Direct Effect and Indirect Effect and Total Effect in Multilevel Path Analysis

\begin{tabular}{|c|c|c|c|c|c|c|}
\hline \multirow{2}{*}{ Pathway } & \multicolumn{2}{|c|}{$\mathrm{DE}$} & \multicolumn{2}{|c|}{ IE } & \multicolumn{2}{|c|}{ TE } \\
\hline & $\mathrm{b}$ & $\beta$ & $\mathrm{b}$ & $\beta$ & $\mathrm{b}$ & $\beta$ \\
\hline \multicolumn{7}{|c|}{ Variance explained in student or within level $\left(\mathrm{R}^{2}=0.399\right)$} \\
\hline LED $\rightarrow$ DIS & $0.151 * *$ & 0.212 & - & - & $0.151 * *$ & 0.212 \\
\hline MOT $\rightarrow$ DIS & $0.150 * *$ & 0.221 & $0.050 * *$ & 0.073 & $0.200 * *$ & 0.294 \\
\hline $\mathrm{CON} \rightarrow \mathrm{DIS}$ & $0.031 * *$ & 0.078 & $0.077 * *$ & 0.194 & $0.109 * *$ & 0.273 \\
\hline $\mathrm{CON} \rightarrow \mathrm{MOT} \rightarrow \mathrm{DIS}^{\#}$ & & & $0.041 * *$ & 0.103 & & \\
\hline $\mathrm{CON} \rightarrow \mathrm{LED} \rightarrow \mathrm{DIS}^{\#}$ & & & $0.023 * *$ & 0.057 & & \\
\hline $\mathrm{CON} \rightarrow \mathrm{PRO} \rightarrow \mathrm{LED} \rightarrow \mathrm{DIS}^{\#}$ & & & $0.014 * *$ & 0.034 & & \\
\hline $\mathrm{ATT} \rightarrow \mathrm{DIS}$ & 0.012 & 0.024 & $0.082 * *$ & 0.167 & $0.094 * *$ & 0.191 \\
\hline $\mathrm{ATT} \rightarrow \mathrm{MOT} \rightarrow \mathrm{DIS}^{\#}$ & & & $0.017 * *$ & 0.034 & & \\
\hline $\mathrm{ATT} \rightarrow \mathrm{CONF} \rightarrow \mathrm{DIS}^{\#}$ & & & $0.008 * *$ & 0.016 & & \\
\hline $\mathrm{ATT} \rightarrow \mathrm{LED} \rightarrow \mathrm{DIS}^{\#}$ & & & $0.032 * *$ & 0.064 & & \\
\hline $\mathrm{ATT} \rightarrow \mathrm{CON} \rightarrow \mathrm{MOT} \rightarrow \mathrm{DIS}^{\#}$ & & & $0.011 * *$ & 0.022 & & \\
\hline $\mathrm{ATT} \rightarrow \mathrm{MOT} \rightarrow \mathrm{LED} \rightarrow \mathrm{DIS}^{\#}$ & & & $0.006 * *$ & 0.011 & & \\
\hline $\mathrm{ATT} \rightarrow \mathrm{CON} \rightarrow \mathrm{LED} \rightarrow \mathrm{DIS}^{\#}$ & & & $0.006 * *$ & 0.012 & & \\
\hline $\mathrm{ATT} \rightarrow \mathrm{CON} \rightarrow \mathrm{MOT} \rightarrow \mathrm{LED} \rightarrow \mathrm{DIS}^{\#}$ & & & $0.004 * *$ & 0.007 & & \\
\hline $\mathrm{DEM} \rightarrow \mathrm{DIS}$ & $0.112 * *$ & 0.257 & $0.098 * *$ & 0.226 & $0.210 * *$ & 0.484 \\
\hline $\mathrm{DEM} \rightarrow \mathrm{MOT} \rightarrow \mathrm{DIS}^{\#}$ & & & $0.019 * *$ & 0.044 & & \\
\hline $\mathrm{DEM} \rightarrow \mathrm{ATT} \rightarrow \mathrm{DIS}^{\#}$ & & & 0.003 & 0.006 & & \\
\hline $\mathrm{DEM} \rightarrow \mathrm{CON} \rightarrow \mathrm{DIS}^{\#}$ & & & $0.011 *$ & 0.026 & & \\
\hline $\mathrm{DEM} \rightarrow \mathrm{LED} \rightarrow \mathrm{DIS}^{\#}$ & & & $0.013 * *$ & 0.031 & & \\
\hline $\mathrm{DEM} \rightarrow \mathrm{ATT} \rightarrow \mathrm{MOT} \rightarrow \mathrm{DIS}^{\#}$ & & & $0.004 * *$ & 0.008 & & \\
\hline $\mathrm{DEM} \rightarrow \mathrm{CON} \rightarrow \mathrm{MOT} \rightarrow \mathrm{DIS}^{\#}$ & & & $0.015 * *$ & 0.034 & & \\
\hline $\mathrm{DEM} \rightarrow \mathrm{ATT} \rightarrow \mathrm{CON} \rightarrow \mathrm{DIS}^{\#}$ & & & $0.002 * *$ & 0.004 & & \\
\hline $\mathrm{DEM} \rightarrow \mathrm{PRO} \rightarrow \mathrm{LED} \rightarrow \mathrm{DIS}^{\#}$ & & & $0.006 * *$ & 0.015 & & \\
\hline $\mathrm{DEM} \rightarrow \mathrm{ATT} \rightarrow \mathrm{LED} \rightarrow \mathrm{DIS}^{\#}$ & & & $0.007 * *$ & 0.016 & & \\
\hline $\mathrm{DEM} \rightarrow \mathrm{CON} \rightarrow \mathrm{LED} \rightarrow \mathrm{DIS}^{\#}$ & & & $0.008 * *$ & 0.019 & & \\
\hline $\mathrm{DEN} \rightarrow \mathrm{ATT} \rightarrow \mathrm{CON} \rightarrow \mathrm{MOT} \rightarrow \mathrm{DIS}^{\#}$ & & & $0.002 * *$ & 0.005 & & \\
\hline $\mathrm{DEM} \rightarrow \mathrm{ATT} \rightarrow \mathrm{MOT} \rightarrow \mathrm{LED} \rightarrow \mathrm{DIS}^{\#}$ & & & $0.001 * *$ & 0.003 & & \\
\hline $\mathrm{DEM} \rightarrow \mathrm{CON} \rightarrow \mathrm{MOT} \rightarrow \mathrm{LED} \rightarrow \mathrm{DIS}^{\#}$ & & & $0.005 * *$ & 0.011 & & \\
\hline $\mathrm{DEM} \rightarrow \mathrm{ATT} \rightarrow \mathrm{CON} \rightarrow \mathrm{LED} \rightarrow \mathrm{DIS}^{\#}$ & & & $0.001 * *$ & 0.003 & & \\
\hline $\mathrm{DEM} \rightarrow \mathrm{ATT} \rightarrow \mathrm{CON} \rightarrow \mathrm{MOT} \rightarrow \mathrm{LED} \rightarrow \mathrm{DIS}^{\#}$ & & & $0.001 * *$ & 0.002 & & \\
\hline \multicolumn{7}{|c|}{ Variance explained in faculty or between Level $\left(\mathrm{R}^{2}=0.984\right)$} \\
\hline $\mathrm{MED} \rightarrow \mathrm{DIS}$ & $-0.453 * *$ & -0.817 & $-0.077 * *$ & -0.139 & $-0.530 * *$ & -0.956 \\
\hline $\mathrm{MED} \rightarrow \mathrm{PRO} \rightarrow \mathrm{DIS}^{\#}$ & & & $-0.037 * *$ & -0.067 & & \\
\hline $\mathrm{MED} \rightarrow \mathrm{ENV} \rightarrow \mathrm{DIS}^{\#}$ & & & $0.031 * *$ & 0.056 & & \\
\hline $\mathrm{MED} \rightarrow \mathrm{CLI} \rightarrow \mathrm{DIS}^{\#}$ & & & $-0.014 * *$ & -0.025 & & \\
\hline $\mathrm{MED} \rightarrow \mathrm{ENV} \rightarrow \mathrm{PRO} \rightarrow \mathrm{DIS}^{\#}$ & & & $0.022 * *$ & 0.039 & & \\
\hline $\mathrm{MED} \rightarrow \mathrm{CLI} \rightarrow \mathrm{PRO} \rightarrow \mathrm{DIS}^{\#}$ & & & $0.001 * *$ & 0.002 & & \\
\hline $\mathrm{MED} \rightarrow \mathrm{ENV} \rightarrow \mathrm{CLI} \rightarrow \mathrm{DIS}^{\#}$ & & & $-0.087 * *$ & -0.157 & & \\
\hline $\mathrm{MED} \rightarrow \mathrm{ENV} \rightarrow \mathrm{CLI} \rightarrow \mathrm{PRO} \rightarrow \mathrm{DIS}^{\#}$ & & & $0.007 * *$ & 0.013 & & \\
\hline $\mathrm{PRO} \rightarrow \mathrm{DIS}$ & $0.140 * *$ & 0.195 & - & - & $0.140 * *$ & 0.195 \\
\hline $\mathrm{CLI} \rightarrow \mathrm{DIS}$ & $-0.173 * *$ & -0.356 & $0.014 * *$ & 0.029 & $-0.159 * *$ & -0.326 \\
\hline $\mathrm{ENV} \rightarrow \mathrm{DIS}$ & $0.049 * *$ & 0.101 & $-0.092 * *$ & -0.189 & -0.043 & -0.088 \\
\hline $\mathrm{ENV} \rightarrow \mathrm{PRO} \rightarrow \mathrm{DIS}^{\#}$ & & & $0.034 * *$ & 0.070 & & \\
\hline $\mathrm{ENV} \rightarrow \mathrm{CLI} \rightarrow \mathrm{DIS}^{\#}$ & & & $-0.137 * *$ & -0.282 & & \\
\hline $\mathrm{ENV} \rightarrow \mathrm{CLI} \rightarrow \mathrm{PRO} \rightarrow \mathrm{DIS}^{\#}$ & & & $0.011 * *$ & 0.023 & & \\
\hline \multicolumn{7}{|l|}{ Cross-level Interaction Effects } \\
\hline $\mathrm{ENV} \rightarrow \mathrm{ATT}$ & $0.291 * *$ & 0.545 & - & - & $0.291 * *$ & 0.545 \\
\hline $\mathrm{CLI} \rightarrow \mathrm{ATT}$ & $-0.500 * *$ & -0.939 & - & - & $-0.500 * *$ & -0.939 \\
\hline
\end{tabular}

Note : 1) $\left.\mathrm{ICC}_{\mathrm{DIS}}=0.065, \mathrm{ICC}_{\mathrm{ATT}}=0.014,2\right) \mathrm{b}=$ Unstandardized Path Coefficient, $\beta=$ Standardized Path Coefficient, 3) $* * \mathrm{p}<.01, * \mathrm{p}<.05$, 4) ${ }^{\#}$ specific indirect effect 


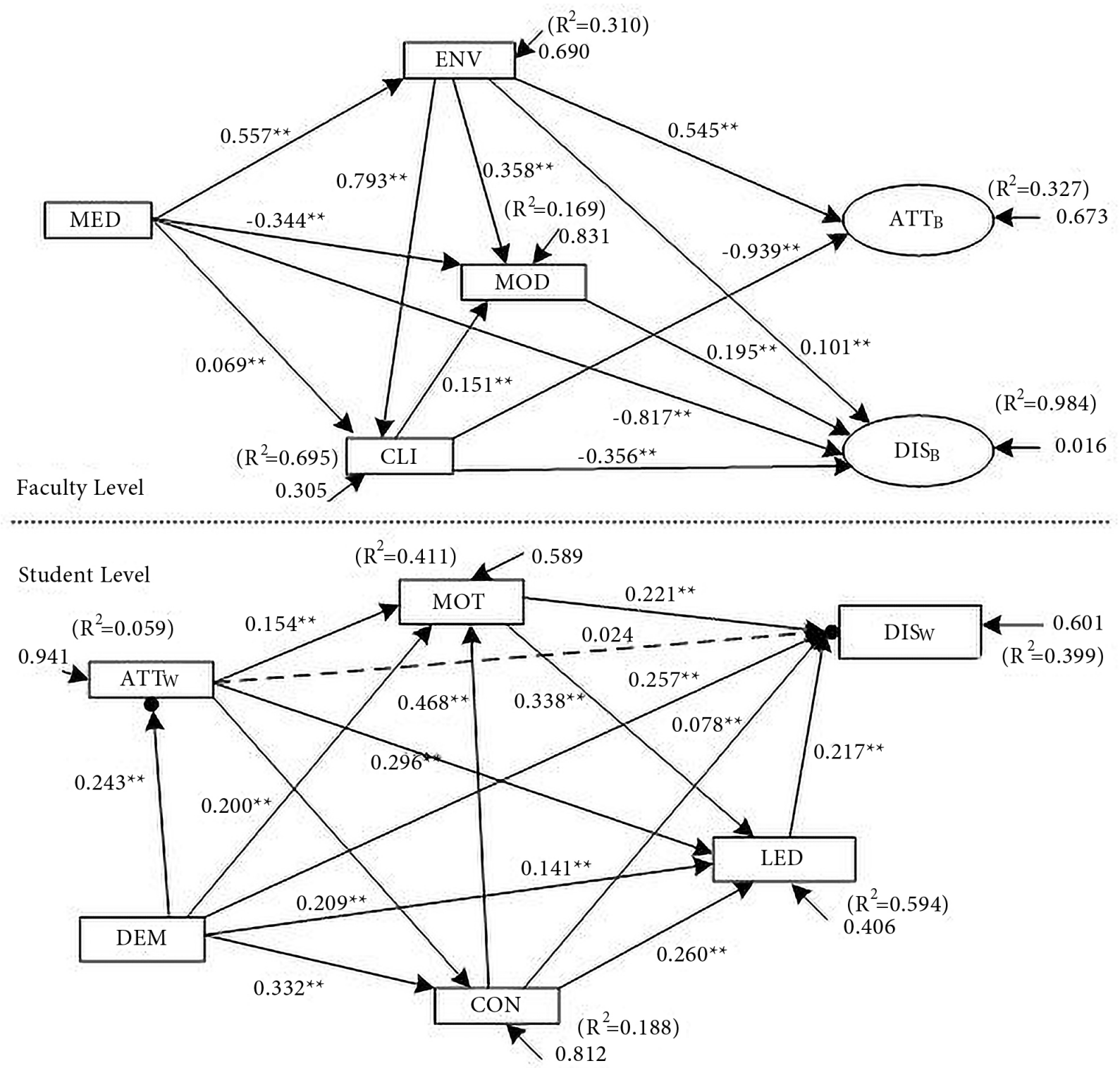

Note: 1) Path coefficients are expressed as standard scores, 2) $* *$ p $<.01, \quad *<.05,3)$ Dotted lines show no statistically significant, 4) The black dots indicate the mean of the variable within level for using as a dependent variable in between level.

Figure 1. Multilevel path analysis model

\section{Conclusions and Implementations}

The objective of this study was to examine factors affecting DIS as good citizens for undergraduates. The finding was based on the assumptions set. The researcher expected that the main causes are the screening of variables, quality of measuring instrument, appropriate sample size, and appropriate statistical analysis with the relationship type and variable structure towards the consistency of the MPA as the hypothetical model and the empirical data.

The "democratic child rearing" was also the most important factor in the model. It found the most positive effect both of DE, IE, and TE. This was as the recommendations of scholars who encouraged parents to adopt democratic rearing in order to support for the development of ethics, morality, and discipline [22] as well as the realization of citizenship [28]. IE indicates 3 outstanding types of DEM: 1) the children are motivated to live with discipline from childhood and then to have DIS behavior, 2) the children have confidence in themselves, motivation to behave with DIS and then to behave with the behavior of DIS, and 3) it leads to LED. After that, they behave DIS. Surprisingly, the researcher found that ATT has no DE on DIS since the previous research showed that the DEM has a positive effect on DIS ([29]; [2]). However, considering the IE and TE revealed that the main role of ATT directly and indirectly to other factors for all 7 paths, especially helping the children to have CON and MOT. It may be possible that there were other factors beyond the scope of this research. It is the result of interaction in one form with ATT. As a result, the effect of ATT on DIS appeared to be positive, but it was not enough to have 
statistical significance.

Referring to the study of influence of faculty level, the "discipline model" was the most important factor. It had the highest positive effect and acted as a mediator, often resulting in a positive path coefficient. The results were consistent with the findings from the research that described the role and relationships of instructor ([27]; [3]; [26]; [18]; [21]), and the relationships with close friends on student behavior ([17]; [12]; [36]). It was possible that the ages of the samples were at this bachelor degree in the late teens. Therefore, the focus was often on the person who plays a close role in the university; instructors and close friends more than a family member [34]. Being so close, they had opportunities for exchange of learning, observation, and imitation to achieve acceptance by the group. They all affect the absorption of social learning; also, the self-discipline of the model ([8]; [34]).

The "discipline environment" was the second most important factor although the results showed negative IE, and TE was not statistically significant. This was in contrast to previous research and ideas ([6]; [1]). On the other hand, considering IE of the 3 paths, it indicated that ENV that is transmitted through the CLI promotes only one pathway that shows the path coefficient in the negative direction. This may be a significant factor in the TE of ENV with no statistical significance. However, the researcher has further hypothesized about the results of this research. The CLI was as a mediator variable and it was found that the effect of ENV was not consistent with the concepts and findings of the past. There should be an in-depth study of the characteristics, approach or type of climate. The CLI had a positive effect on DIS and other related factors.

The "media effect" and "disciplined climate" were the most worrying factors in the model because of negative effect on DIS and the PRO was at very high level (both DE and IE, and TE) even though there was a lot of evidence to show the negative effect of such factors (e.g., [15]; [36]; [16]; [10]). On the other hand, in the context of Thailand, there was also a lack of empirical evidence to explain the negative effects of free media presentation on the self-discipline behavior among students in higher education. The media presenters are relatively free to present content and the features to consumers, which the opportunity to access such content can be done at any time. It has more channels than in the past, which there were few sources, such as TV or radio [8]. According to a survey of information on the use of portable electronic devices in Thailand recently, it has revealed that about $93 \%$ of students in Chiang Mai University have a smartphone for setting alarms and reminders, and having a conversation, which they think that this is more useful in daily lives than for self-development purposes [9]. In addition, knowledge and attitudes towards the use of parental technology media are much slower than in the student population. As a result, the oversight of the reason for the use of creative media and media literacy has not been thoroughly and seriously implanted before the student enters into his or her own independent higher education.

As the effect of CLI of Chiang Mai University, the findings showed the negative effect on DIS . The researcher noted that the student activities are diversified in aspects and diversified patterns, have the goal to promote student discipline and living in the university. Moreover, the environment is beautiful so that it offers the opportunity for international visitors to visit the beautiful campus throughout the year. However, there are four major constraints to all activities: 1) student activities are aligned with student needs, 2) activities are activities that were previously organized, 3) student groups are relatively small compared to the total number of students, and 4) there is a lack of continuity to raise awareness and attitudes towards discipline. Such characteristics may influence the estimation of path coefficients of discipline climate and other factors, both at the faculty and student level.

In summary, DIS of the students is a fundamental factor from the rearing, which is the foundation for incubation, cultivation of desirable characteristics for all children. Parents should use parenting with love and warmth in the right way, give reason for instruction, teach children to be familiar with the importance of regulation and realize the value of keeping the rules. These can lead to the better attitude, confidence in the discipline. It helps children grow into adults with immunity to the society with the rules without breaking it and do not cause any problems to the others in public and behind [18]. Moreover, the development of DIS of university students should review the guidelines for activities related to the development of DIS, analyze goals, activities, student participation, duration and continuity of each project that affects each student. In addition, the morale of the disciplines of the personnel and students is more pronounced including there should have the improvement of the physical environment in the university and each faculty that facilitates the discipline, awareness, and absorption of discipline as in their daily lives ([34]; [8]). Furthermore, there should be a study on the promotion of media literacy to students as well as parents for being able to use the channel to consume content from the media critically and creatively.

This study is to capture a framework for studying the factors affecting self-discipline from the results of the theoretical review and related research findings. Most of the previous study was done by the group of primary and secondary school students, which differed from this group of the population of this study. Therefore, the interesting variables were selected to conduct the in-depth study such as the nature or type of media, the content of the media ) e.g., Facebook, Instagram, Snapchat (or the media habits of students with different self-discipline [5], the mediation effect of DIS and gender as transmission variables on causal relationships between factors and students' achievement [11], a meta-analysis of research related to the 
development of innovation to promote DIS of students, and the characteristics/indicators of DIS that affect ATT among faculty groups .The results of this study will lead to a clear and concise explanation of the cause of DIS of students in higher education and can be the information for the students to develop students into the future quality citizens in society.

\section{Acknowledgements}

This research article used to be selected for the presentation at the $10^{\text {th }}$ World Conference on Educational Sciences, Prague, Czech Republic, on February $2^{\text {nd }}, 2018$ and received the comments of experts and attendees in order to improve the article to be more complete. I would like to thank to those involved in the improvement on this occasion. Moreover, the researcher would like to thank Chiang Mai University for the support of the scholarship and the budget for this study, thank students for providing quality information. I also would like to show my gratitude to the instructors and students in the field of Educational Evaluation and Research, Faculty of Education, Chiang Mai University for providing technical feedback and helping to gather information, checking and recording data with the limited time until the study is completely done.

\section{REFERENCES}

[1] K. N. Alotaibi. The learning environment as a mediating variable between self-directed learning readiness and academic performance of sample of Saudi nursing and medical emergency students. Nurse Education Today, 36, 249-254, 2016.

[2] B. Alyanak, A. Kılınçaslan, H. S. Harmanc1, S. K. Demirkaya, T. Yurtbay, H. E. Vehid. Parental adjustment, parenting attitudes and emotional and behavioral problems in children with selective mutism. Journal of Anxiety Disorders, 27, 9-15, 2013.

[3] B. Aydin. Teacher concepts on students' obtaining self-control. Procedia- Social and Behavioral Sciences, 1, 1244-1248, 2009.

[4] A. Bandura. Self-efficacy: The exercise of control. NY: Freeman, 1997.

[5] S. C. Boyle, A. M. Earle, J .W. LaBrie, K. Ballou. Facebook dethroned: Revealing the more likely social media destinations for college students' depictions of underage drinking. Addictive Behaviors, 65, 63-67, 2017.

[6] M. Brault, M. Janosz, I .Archambault. Effects of school composition and school climate on teacher expectations of students: A multilevel analysis. Teaching and Teacher Education, 44, 148-159, 2014.

[7] A. W. Combs. Achieving self-discipline: Some basic principle. Theory into Practice, 24, 260-263, 2001.
[8] R. L. Curwin, A. N. Mendler. Discipline with dignity. VA : Association for Supervision and Curriculum Development, 1988.

[9] S. Damrongpanit, R. Samuttai, K. Srisuk, S. Nguenyuang, N. Intanate. The development of indicators for utilising portable electronic devices of the undergraduates. The Social Sciences, 11(21), 5080-5089, 2016.

[10] K. V. Eck, S. R. Johnson. A. Bettencourt. S. L. Johnson. How school climate relates to chronic absence: A multi-level latent profile analysis. Journal of School Psychology, 61, 89-102, 2017.

[11] Y. Gong, D. Rai, J. Beck, N. T. Heffernan. Dose self-discipline impact students' knowledge and learning? Educational Data Mining, 61-70, 2009.

[12] S. B. Horner, G. D. Fireman, E. W. Wang. The relation of behavior, peer status, race, and gender to decisions about school discipline using CHAID decision trees and regression modeling. Journal of School Psychology, 48, 135-161, 2010.

[13] L. Hu, P. M. Bentler. Cutoff criteria for fit indexes in covariance structure analysis: Conventional criteria versus new alternatives. Structural Equation Modeling: A Multidisciplinary Journal, 6(1), 1-55, 1999.

[14] R. B. Kline. Principles and practices of structural equation modeling ( $3^{\text {rd }}$ ed.). NY: Guilford Press, 2011.

[15] T. R. Konold, D. Cornell. Measurement and structural relations of an authoritative school climate model: A multilevel latent variable investigation .Journal of School Psychology, 53, 447-461, 2015.

[16] W. W. F. Lau. Effects of social media usage and social media multitasking on the academic performance of university students. Computers in Human Behavior, 68, 286-291, 2017.

[17] R. Lewis, S. Romi, X. Qui, Y. J. Katz. Teachers' classroom discipline and student misbehavior in Australia, China, and Israel. Teaching and Teacher Education, 21, 729-741, 2005.

[18] C. Li, J. Dang, X. Zhang, Q. Zhang, J. Guo. Internet addiction among Chinese adolescents: The effect of parental behavior and self-control. Computers in Human Behavior, 41, 1-7, 2014.

[19] J. Lu, Q. Hao, M. Jing. Consuming, sharing, and creating content: How young students use new social media in and outside school. Computers in Human Behavior, 64, 55-64, 2016 .

[20] R. G. Lucas-Thompson, D. J. Graham, E. Ullrich, D . MacPhee. General and food-selection specific parenting style in relation to the healthfulness of parent-child choices while grocery shopping. Appetite, 108, 353-360, 2017.

[21] D. P. Martin, S. E .Rimm-Kaufman. Do student self-efficacy and teacher-student interaction quality contribute to emotional and social engagement in fifth grade math? Journal of School Psychology, 53, 359-373, 2015.

[22] C. C. Mccoby, J. A. Martin. Socialization in the context of the family :Parent-child interaction. In E. M. Hetherington (Ed.) \& (P.H .Mussen, Gen. Ed.), Handbook of child psychology. Vol. 4: Socialization, personality, and social developmental (4 ${ }^{\text {th }}$ Ed.). NY: Wiley, 1983. 
[23] C. McGuire, G. D. White. Social-class influences on discipline at school .Educational Leadership, 229-236, 1957.

[24] L. Muthén. B, Muthén. Mplus: Statistical Analysis with Latent Variable ( $7^{\text {th }}$ ed.). CA: Muthén \& Muthén, 2015.

[25] K. W. O’Connor, G. B. Schmidt, M. Drouin. Suspended because of social media? Students' knowledge and opinions of university social media policies and practices. Computers in Human Behavior, 65, 619-626, 2016.

[26] D. M. Pane. Viewing classroom discipline as negotiable social interaction: A communities of practice perspective. Teaching and Teacher Education, 26, 87-97, 2010.

[27] M. Pšunder. How effective is school discipline in preparing students to become responsible citizens? Slovenian teachers' and students' views. Teaching and Teacher Education, 21, 273-286, 2005.

[28] R. Rothstein. Towards a composite index of school performance. The Elementary School Teacher, 100(5), 409-441, 2000 .

[29] H. Saricam, M. Halmatov, S. Halmatov, I. Celik. The investigation of child rearing attitudes of families living in rural and urban area (Turkish sample). Procedia -Social and Behavioral Sciences, 46, 2772-2776, 2012.

[30] D. R. Shaffer. Social and Personality Development ( $6^{\text {th }}$ ed. $)$. CA: Wadsworth, 2009.

[31] C. T. Ugurlu, K. Beycioglu, Y. Kondakcı, M. Sincar, M. C. Yildırım, N. Ozer, A. Oncel. The views of teachers towards perception of discipline in schools. Procedia-Social and Behavioral Sciences, 197, 120-125, 2015.

[32] J. L. Winkler, M. E. Walsh, M. D. Blois, J. Maré, S. C . Carvajal. Kind discipline: Developing a conceptual model of a promising school discipline approach. Evaluation and Program Planning, 62, 15-24, 2017.

[33] A. Winsler, A. L. Madigan, S. A .Aquilino. Correspondence between maternal and paternal parenting styles in early childhood. Early Childhood Research Quarterly, 20, 1-12, 2005.

[34] C. H .Wolfgang. Solving Discipline Problems: Methods and Models for Today's Teachers $\left(3^{\text {rd }}\right.$ ed.). MA: Allyn and Bacon, 1995.

[35] S. Yazdani, G. Daryei. Parenting styles and psychosocial adjustment of gifted and normal adolescent. Pacific Sciences Review B: Humanities and Social Sciences, 2, 100-105, 2016.

[36] W. Yoo, J. Yang, E. Cho. How social media influence college students' smoking attitudes and intentions. Computers in Human Behavior, 64, 173-182, 2016. 